\title{
LVI. Theoretical optics since 1840.-A Survey
}

\section{R.T. Glazebrook D.Sc. F.R.S.}

To cite this article: R.T. Glazebrook D.Sc. F.R.S. (1903) LVI. Theoretical optics since 1840._A Survey, Philosophical Magazine Series 6, 5:29, 537-543, DOI: 10.1080/14786440309462956

To link to this article: http://dx.doi.org/10.1080/14786440309462956

\section{Published online: 15 Apr 2009.}

Submit your article to this journal 준

Џll Article views: 5

Q View related articles $\sqsubset$ 
longitudinal magnetic induction of 17,500 c.G.s. lines per sq. em., the value $10 \cdot 2$ per cent. was found; and this value is in tolerable agreement with those quoted in an earlier part of the paper as obtained by the direct method.

\section{Summary of Results.}

The change in the thermal conductivity of bismuth produced by magnetic field is very small ; for a transverse field of 3550 it is considerably less than $\frac{1}{2}$ per cent., and it is scarcely measurable even in higher fields by any of the methods used.

As tested by the bridge method, mild steel suffered a reduction of its conductivity of $3 \cdot 3$ per cent. for an increase of transverse field of 7500 , and a reduction of $2 \cdot 1$ per cent. for an increase of 6700 . The reduction $3 \cdot 1$ per cent. was observed for the same material by the method of direct measurement on application of a transverse field of 6500 .

The effect of a longitudinal field of 51 c.G.S. on the conductivity of mild steel was to diminish it by about 4 per cent.

In the case of soft iron, as tested by direct measurement, a longitudinal field producing a magnetic induction of 16,000 per sq. $\mathrm{cm}$. diminished the conductivity by about 10.5 per cent.; while the effect of transverse field is comparatively small-about 1 per cent. for a field of 7850 ; by the bridge method the effect of a longitudinal induction of 17,500 was found to be a diminution of conductivity of $10 \cdot 2$ per cent.

I beg to express sincerest thanks to Prof. J. J. Thomson for continual encouragement and assistance.

Cavendish Laboratory, Cambridge.

LVI. Theoretical Optics since 1840,-A Survey. By R. T. Glazebrook, D.Se., F.R.S.*

GIR GEORGE STOKES took his degree in 1841 ; the $\checkmark$ first of the papers contained in his Collected Works was read in 1842: he became Lucasian Professor in 1849.

Speaking as I do so soon after his death, it is, perhaps, not unnatural to look back over the progress of our Science during the sixty years for which he has been one of the most prominent of its exponents.

To attempt such a task in any completeness would need a fuller knowledge and an abler pen than mine; will you, bowever, bear with me if I take one corner of the field covered by his activities and attempt a brief survey of this.

* Communicated by the Physical Society, being a portion of the Presidential Address delivered on February 13, 1903. 
It is, perhaps, the more necessary, for I think it is not always recognized how much of our knowledge of Optical Science is due to Stokes. It was be who first verified with any degree of exactness Huyghens' construction for the refraction of light at a uniaxial crystal ; the interpretation of Kirchhoff's discovery of the coincidence between the dark lines of the solar spectrum and the bright lines of certain incandescent solids and gases is due to him, and on this the whole of spectrum analysis rests; he explained the phenomena of fluorescence, and as an old man, some years ago, expounded in his own unrivalled manner the origin of the Röntgen rays and their connexion with the kathode rays. The analysis of a plane wave of light into its constituent parts, and the first dynamical account of diffraction, are due to him; and his experiments, if we accept any modification of the elasticsolid theory of light as true, settled that Fresnel's explanation of the cause of refraction, rather than that of Neumann and MacCullagh, is the right one.

In his brilliant Rede Lecture, Cornu writes :-

"The study of the properties of waves, looked at from every aspect, is then at present the really fruitful path.

"It is that which Stokes, in his double capacity of mathematician and physicist, has followed.... All bis beautiful investigations, whether in hydrodynamics or in theoretical or experimental optics, relate to the transformations which waves undergo in the diverse media through which they pass.

"In the varied phenomena which he has discovered or analysed, movement of fluids, diffraction, interference, fluorescence, Röntgen rays, this guiding idea that I have pointed out is ever visible, and it is this which bas made the scientific life of Sir George Stokes one harmonious whole."

Let us consider then very briefly the progress of theoretical optics since the days of Stokes' first paper on the subject: "On the Theories of the Internal Friction of Fluids in Motion, and of the Equilibrium and Motion of Elastic Solids"*. The advance in the early part of the century had been most marked. The discovery of the principle of interference by Young, and the brilliant work of Augustin Fresnel, who had covered the ground with giant strides, had placed the undulatory theory on a firm footing, but there was no consistent view of the subject which would account even for the facts then known on a rational basis.

Fresnel's theory of double refraction was not dynamical; he arrived at it in the first place by purely geometrical reasoning, based on Huyghens' construction, and only attempted at

* Camb. Phil. Trans. viii. (1845). 
a later date to give it a mechanical basis. In this attempt he failed. "If we reflect," says Stokes, "on the state of the subject as Fresnel found it and as he left it, the wonder is not that he failed to give a rigorous dynamical theory, but that a single mind was capable of effecting so much."

Between the days of Fresnel and Stokes great men had worked at the subject. Navier, Poisson, and Cauchy in France; Neumann in Germany ; MacCullagh in Dublin ; and George Green in Cambridge, had all contributed their share, and the results were somewhat confusing.

MacCullagh and Neumann, treating the æther as an elastic solid, had obtained on certain hypotheses Fresnel's laws for reflexion and refraction, and his theory of double refraction. Green, using a somewhat different method, had shown, apparently, that the tangent law was only an approximation to the truth, while the wave-surface could only be deduced from the true equations of an æolotropic elastic solid by some forced and improbable relations between the constmnts.

According to all the theories, two waves in general can traverse an elastic medium, the one travelling with velocity $\sqrt{\mathrm{A}} / \rho$, the other with velocity $\sqrt{\mathrm{B}} / \rho$ where $\mathrm{A}$ and $\mathrm{B}$ are two constants. Of these the first consists of longitudinal, the second of transverse vibrations; and since there is no evidence of the former wave in optics, the constant A must either vanish or be infinite.

Neumaun's theory assumed A to vanish ; Green had shown that for an elastic solid with free boundaries the condition of stability demanded that $A-4 / 3 \mathrm{~B}$ should be positive, and hence he assumed $A$ to be infinite. On this view of the æther he was clearly right. Such was the position of the problem in 1839 , the year in which the papers of Green, MacCullagh, and Cauchy were published. Stokes' earliest paper on the subject, written when he was 26 years old, deals with the properties which we must assign to the æther if we are to explain the facts observed. To propagate transverse waves it must behave to light motions as an elastic solid ; the constancy of the length of the year, and other astronomical results, show that it opposes no sensible resistance to the motion of the earth and the planets, for such motions it has the properties of a perfect fluid.

He distinguishes-the fact is well-known now, but it was a great step then-between the two kinds of elasticity, rigidity and resistance to compression. B is a measure of the rigidity, $\mathrm{A}-4 \mathrm{~B} / 3$ of the resistance to compression. For a fluid. then, which is practically incompressible, the ratio of $A$ to $B$ may be very great, as Green requires it, while in Stokes' 
view it is still possible that for the tiny motions involved in the propagation of light the fluid may have rigidity.

However, be this satisfactory or not, and the difficulty is one which occurs in every elastic-solid theory of Optics, the result remains that an elastic-solid theory is not consistent with the facts. The phenomena of reflexion and refraction at the bounding surface of two media may be due either to a change in density or to a change in rigidity.

Green's theory of refraction assumes the change to be one of density, the rigidity of the æther in all isotropic media is the same; his theory of double refraction assumes this to arise from a variation of the rigidity in different directions within a crystal.

These difficulties are clearly exposed in Stokes' Report to the British Association in 1862, in which he also shows that MacCullagh and Neumann's theory is impossible so long as the potential energy of the rther when transmitting light is assumed to be that of a strained elastic solid. If we suppose the xther to differ from an ordinary elastic solid but to possess what has been called rotational elasticity, in consequence of which it opposes forces tending to cause molecular twist to an extent proportional to the twist, then MacCullagh's form of the potential energy is obtained and his conclusions hold. From this point of view the matter has been developed of late years by Larmor.

The Report of 1862 deals with another matter, specially interesting to myself, because in later years Stokes encouraged me to pursue it.

Up to that date the experiments to verify Huyghens' construction for a uniaxial crystal had been of the roughest character. Stokes devised a method of testing the construction to a very high degree of accuracy and carried it into effect for lceland spar. The results are very briefly referred to ; they were published later, but hardly in greater detail, at Lord Kelvin's urgent request, in the Proceedings of the Royal Society.

The outcome was that while for a uniaxial crystal at least Huyghens' construction was undoubtedly true, no theoretical basis could be given for it.

It was left to Maxwell to carry the question a stage further. He showed that the laws which regulate the propagation of electric force in a crystal are identical with those of light, while experiment proved that the velocity of light is the same as that of an electric disturbance, and hence we have the electromagnetic theory of light.

It should be noted, however, that this theory, as Maxwell 
left it, is not mechanical. Electric displacement and magnetic force are vector quantities which accompany each other in a changing electric field. They satisfy certain equations; and it follows from these, and the result is verified by experiment, that they are propagated according to the same laws as light. It is reasonable to suppose that the periodic disturbance which constitutes light is very intimately connected with one or other of these ; the supposition that it is identical with Maxwell's electric displacement leads to consequences consistent with fact, and, indeed, in the able hands of those who have developed the theory has been the fruitful means of correlating many varied phenomena ; but it does not tell us what electric displacement is, or how it is related to the movements of the æther; neither does it enlighten us as to the structure and mechanical properties of the æther, beyond the simple fact that in the æether transverse waves only are propagated, no forces can be called iuto play which tend to set up a pressural wave. Maxwell himself attempted to formulate a mechanical model of the rether, and to some extent succeeded. Luord Kelvin, so fertile in his thoughts, has made various suggestions, we will return to one later. Today the electron theory of electricity, thanks mainly to the brilliant work of Stokes' Cambridge colleague, J.J. Thomson, holds the field; but the relation of the electron to the ather and the mechanism by which electrons produce ather waves have yet to be discovered.

Larmor's suggestion that the flow of æther constitutes magnetic force, while a twist in an æther endowed with rotational elasticity produces electric displacement, forms perhaps the most consistent picture of the process which we possess.

Lord Kelvin, indeed, in 1888 suggested a structure for the rether which allows of a homogeneous mechanical account of optical phenomena being given.

On this view the resistance to compression of the rther is negative, if free it would collapse, but the necessary stability is given by the supposition that it is fixed at the boundaries; it is a structure like a collection of soap-films stretched across a wire framework; if the connexion be broken the whole collapses, so long as it remains the system can propagate transverse waves. With such an rether there is no difficulty in giving a consistent account of Optics, but it is difficult to imagine that the ather has such properties. I believe, however, that Lord Kelvin now thinks that a slight modification of his original hypothesis will lead to the same result so far as opties are concerned, but will enable him to get over the difficulty of postulating fixed boundaries.

Phil. Mo.g. S. 6. Vol. 5. No. 29. May 1903. 
On such an hypothesis the molecular velocity of the æther might measure magnetic force, while electric displacement would then be proportional to the curl of the twist, or we might adopt the analogy suggested by Heaviside ('Electrician,' Jan. 23, 1891), and developed, as I have said, by Larmor, according to which the kinetic energy measures the magnetic force and the twist the electric displacement.

The electromagnetic theory, though it does not rest on a mechanical basis, has linked together optical and other phenomena in a striking fashion. The advance from the days of Green bas been a great one.

And leaving now the general theory, the development of its details bas not been less striking. On all sides there has been advance, and along most of the lines of advance Stokes was a pioneer.

Newton's difficulty in accepting the undulatory theory was really solved when Young enunciated the principle of interference, but it needed Fresnel's experiments to convince men of its truth. It was clear, of course, that the effect at any point due to a wave of light could be calculated by finding the effect due to each element of the wave and summing these; but Stokes, in his papers on diffraction (1851), was the first to establish a correct expression for the effect produced at a distant point by an element of the wave and to show how these effects were to be summed.

The germ of all that has been discovered by means of spectrum analysis is contained in his explanation of Kirchhoff's original experiment, often quoted by Lord Kelvin, and from his paper on "Fluorescence" have sprung the modern theories of dispersion, including anomalous dispersion. On this point the note he has added to this paper in the third volume of his Collected Works has a special interest. Although he did not fathom the connexion between rther and matter, and, on the whole, the criticisms passed by later writers on his theory of aberration are to be accepted as justified, his papers must be studied by any one who is anxious to penetrate the mystery, and did much to put the facts in a clear light.

My survey is, I realize, entirely inadequate; it is but a fraction even of the corner of the field I set out to examine that I. have covered, but I must stop. I have said enough, I hope, to show that progress has been continuous and marked, and in no small degree that progress has been due to the work of Sir George Stokes.

I had intended to bring before you some more practical questions connected with the work of my own Laboratory. 
These must await a more fitting opportunity; meanwhile let me conclude as I began, by thanking you very heartily for placing me in this position, and assuring you of my desire to forward your best interests.

LVII. On the Numerics of the Elements.-Part III. By Edmund J. Mrus, D.Sc., F.R.S.*

T has been shown in previous parts $\dagger$ that the numerics of the elements are of the form

$$
y=p n-n\left(\frac{n}{n+1}\right)^{x}
$$

where $p$ represents the number of the periodic group, $n+1$ the number of periods in the system, and $x$ the integral ordinal within a given group. So far as is known, all the numerics of the existing elementary bodies, excepting that of hydrogen, are included in the above equation when $n=15$; and the range in value is from $y=0$ to $y=240$.

It has been objected $\ddagger$ to this method of representation that it includes an infinite number of elements within the range indicated. Ample precedent, however, for this is found in the phenomena of Cumulative Resolution $\S$. In the denitration of bismuthic nitrate by water, for instance, there are three distinct continuous stages :-

$$
\begin{aligned}
& \text { I. } n \mathrm{Bi}_{2} \mathrm{O}_{3} .3 \mathrm{~N}_{2} \mathrm{O}_{5}-(n-1) \mathrm{N}_{2} \mathrm{O}_{5}=\mathrm{Bi}_{2 n} \mathrm{O}_{3 n} . \mathrm{N}_{4 n+2} \mathrm{O}_{10 n+5} \text {, } \\
& \text { and at infinity } \mathrm{Bi}_{2} \mathrm{O}_{3} \cdot \mathrm{N}_{4} \mathrm{O}_{10} \text {. } \\
& \text { II. } n \mathrm{Bi}_{2} \mathrm{O}_{3} \cdot 2 \mathrm{~N}_{2} \mathrm{O}_{5}-(n-1) \mathrm{N}_{2} \mathrm{O}_{5}=\mathrm{Bi}_{2 n} \mathrm{O}_{3 n} . \mathrm{N}_{2 n+2} \mathrm{O}_{5 n+5} \text {, } \\
& \text { and at infinity } \mathrm{Bi}_{2} \mathrm{O}_{3} \cdot \mathrm{N}_{2} \mathrm{O}_{5} \text {. } \\
& \text { III. }{ }_{n} \mathrm{Bi}_{2} \mathrm{O}_{3} \cdot \mathrm{N}_{2} \mathrm{O}_{5}-(n-1) \mathrm{N}_{2} \mathrm{O}_{5}=\mathrm{Bi}_{2 n} \mathrm{O}_{3 n} \cdot \mathrm{N}_{2} \mathrm{O}_{5} \text {, } \\
& \text { and at infinity } \\
& \mathrm{Bi}_{2} \mathrm{O}_{3} \text {. }
\end{aligned}
$$

In the first stage ratios are known for $n=\cdot 1$ and 1 ; in the second, for $n=2$; in the third, for $n=\frac{6}{5}, \frac{5}{4}, \frac{4}{3}, 1$, and $\infty$.

Another objection has been raised to the method that it is too easily applicable to any numeric. This objection, however, is not so much a criticism of the mathematical method, as a censure on the weakness of experimental processes. These, in the most favourable cases, cannot be depended upon more nearly than 02 ; and the mathematical method can only follow them. So far, increasing experimental accuracy has been attended by a closer coincidence with the theory. The

* Communicated by the Author.

† Phil. Mar. 1884, vol. xviii. p. 393; 1886, vol xxi. p. 151.

$\ddagger$ Ibid. 1902, vol. iv. p. 103 . \$ Ibid. 187t, vol. iii. p. 492.

$$
202
$$

